\title{
Features of Acute Mineralocorticoid Excess from ACTH Secreting Bronchial Tumour
}

\author{
Mansour Seidahmad, Firas JS Haddadin , Khin Swe Myint
}

Diabetes and Endocrinology

ACTH secreting bronchial cancer can present with rapid fluid retention than typical Cushing's picture. High index of suspicion is needed for any such presentation.

\section{Initial presentation and assessment:}

- A 77 year old man with Type 2 Diabetes treated with oral hypoglycaemic agents only. (previously well control with HbA1c of $42 \mathrm{mmol} / \mathrm{mol}$ ) presented acutely unwell, with weakness, intermittent breathlessness, and worsening glycaemic control

- His body weight was $74.5 \mathrm{~kg}$, he had mild bilateral legs oedema, BP of 190/100mmHg, scattered expiratory wheeze, $\mathrm{SaO}_{2} 91 \%$ and $\mathrm{PO}_{2} 7.8 \mathrm{mmHg}$ on room air. Chest $\mathrm{XR}$ on admission reported; chronic right Lower lobe changes and a bulky Left hilum.

- Plasma Glucose was $22.4 \mathrm{mmol} / \mathrm{l}$, potassium $2.4 \mathrm{mmol} / \mathrm{l}$, and sodium of $145 \mathrm{mmol} / \mathrm{l}$.

- He was treated for heart failure, started on Insulin therapy and triaged to endocrinology for Hyperglycaemia. Hypokalaemia was refractory to potassium infusion.

\section{Further investigations and management:}

- Echocardiogram was normal.

- CT Abdomen and chest confirmed $5 \mathrm{~cm}$ left hilar mass with mediastinal lymphadenopathy, small bilateral pleural effusion, consistent with bronchial carcinoma and potential metastasis to both adrenals.

- Despite lack of Cushing's feature, Ectopic ACTH secretion was suspected.

- Urgent random serum Cortisol at $5 \mathrm{pm}$ was very high at $5294 \mathrm{nmol} / \mathrm{L}$ with high plasma ACTH of $249 \mathrm{ng} / \mathrm{L}$ (normal $<50$ ), 24hour Urinary Free Cortisol level was massive at 29211nmol/24hr (normal 50-300).

- He deteriorated within 48 hour with significant fluid retention, $5.5 \mathrm{~kg}$ weight gain and pleural effusion requiring chest drain. Subsequent confirmatory test for Cushing's syndrome was deemed unnecessary.

- He was started on Metyrapone with dose actively up-titrated (1g tds in 12 days) against the mean serum cortisol day series, achieving mean cortisol of $980 \mathrm{nmol} / \mathrm{l}$.

- Spironolactone therapy initiated. The patient responded well, features of mineralocorticoid excess largely resolved (6 kg weight loss) and was able to undergo bronchoscopy, which confirmed small Cell Bronchial Carcinoma.

Cortisol Day Curve
\begin{tabular}{|c|c|c|}
\hline Time & $\begin{array}{c}\text { Cortisol (nmol/L) } \\
\text { on Metyrapone } 0.5 \mathrm{gr} \text { TDS }\end{array}$ & $\begin{array}{c}\text { Cortisol (nmol/L) } \\
\text { on Metyrapone 1gr TDS }\end{array}$ \\
\hline $09: 00 \mathrm{hrs}$ & 2783 & 1531 \\
\hline $11: 00 \mathrm{hrs}$ & 2138 & 1012 \\
\hline $13: 00 \mathrm{hrs}$ & 2498 & 1048 \\
\hline $15: 00 \mathrm{hrs}$ & 1694 & 721 \\
\hline $17: 00 \mathrm{hr}$ & 1902 & 597 \\
\hline
\end{tabular}

\section{CT Images}

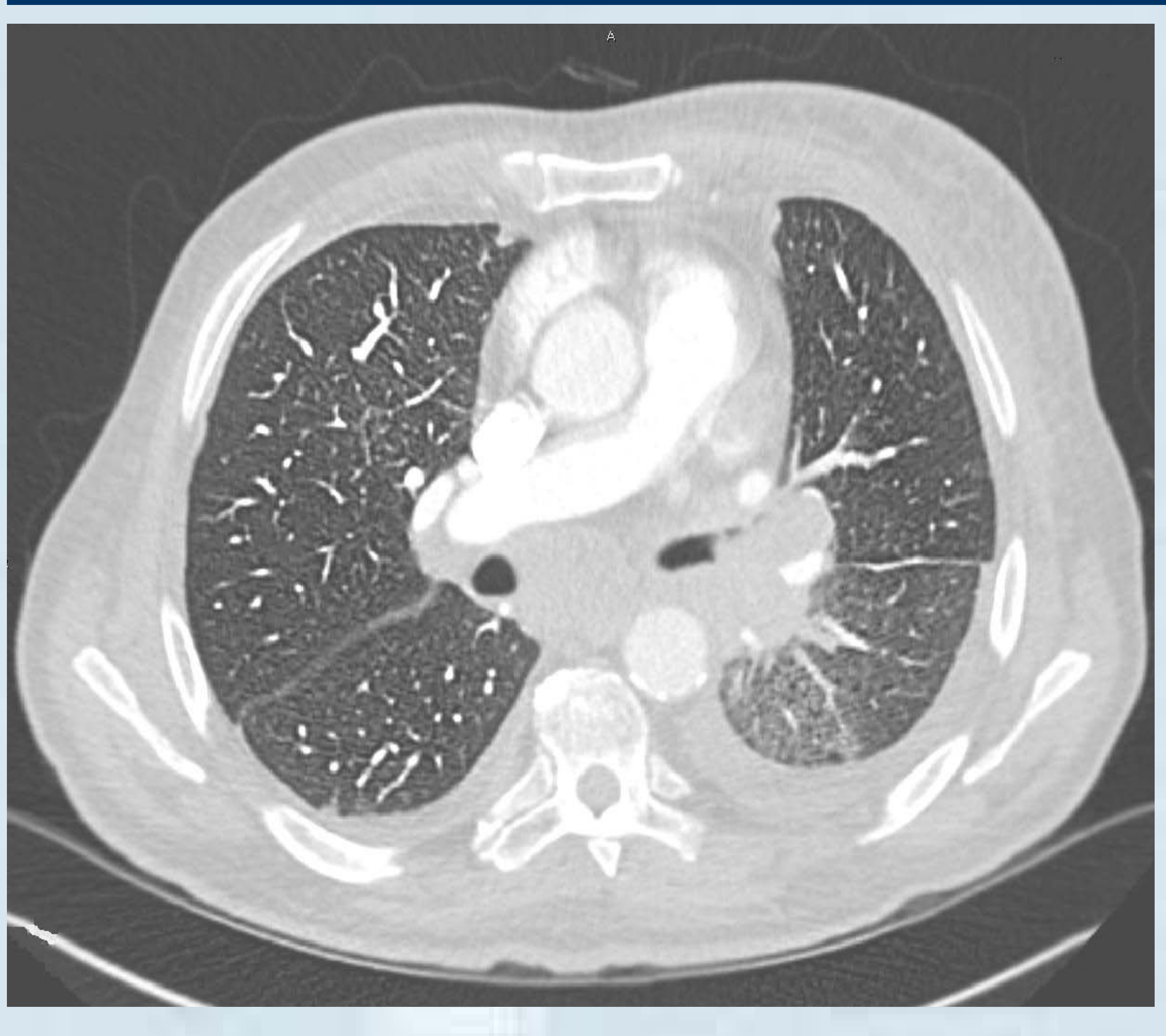

Image1: CT chest with bulky Left hilar mass, most likely to be due to primary bronchogenic carcinoma

\section{Discussion:}

- Rapidly progressing ACTH secreting bronchial tumour will not present with typical feature of Cushing's Syndrome.

- High index of suspicion of such a potential diagnosis is crucial.

- Bulky adrenals in this case were likely ACTH driven not metastasis (altering the staging).

- Metyrapone remained the first line of therapy improving metabolic changes ${ }^{1}$.

1-BMJ. 1977 July 23; 2(6081): 215-217.

2- European Journal of Endocrinology (2006) 155 725-733. 